\title{
Metaplasia of Malignant Cells Present
}

National Cancer Institute

\section{Source}

National Cancer Institute. Metaplasia of Malignant Cells Present. NCI Thesaurus. Code C60749.

Transformation of malignant cells with a specific differentiation to different morphologic types. 